\title{
Improvement of learning quality in manufacturing technology: a case study
}

\author{
Ionela Magdalena Rotaru, ${ }^{1, *}$ \\ ${ }^{1}$ Lucian Blaga University of Sibiu, Industrial Engineering and Management Department, Victoriei, 10, \\ 550025, Sibiu, Romania
}

\begin{abstract}
The paper presents the initial part of a study designed to understand the place of the present generation of engineering students in the global picture of their working life. The education represents an inestimable good that accompanies peoples through their existence. Higher education is the place were teenagers with different profiles modelled by their families, studies; experiences and so on come to meet, in most cases, the final education platform before employment. In light of this the higher education has the major role of prepare the students with the knowledge and skills appropriate to the labour market. That means with the knowledge and skills they need and their future employers are looking for. It involves a huge effort, dedicated to the transfer of knowledge and skills with a success rate as high as possible. To achieve this the study programs and the teaching methods must embody both objectives: to be tailored for the students and to meet the employers needs. That places the higher education on the border of the two parties, its role in achieving the outlined objectives being major.
\end{abstract}

\section{Introduction}

The role of higher education to ensure the transition from student to employee requires the fulfillment of major demands such as:

- Provide specific knowledge aligned with current requirements. In automotive area, where the boundaries are in continuous movement, the alignment to the new technologies is a necessity in order to survive in the competition "Today, the practice of engineering needs to change further because of the demands for technologies and products that exceed existing knowledge bases and because the changed professional environment in which engineers need to operate. That change must be encouraged and facilitated by change in engineering education" [1].

- Engineer's role is becoming more complex and this represents one of the challenges the education faces "We have to change what we expect from engineers, and we have to turn out our graduates with broader skills, interests, and abilities...I need graduates who can speak before an audience to make a point...Engineers must be able to write reports, studies...." [2].

- The present generation, known also as Millennial generation, differentiates from the previous generations through their preferences for collaborating, connecting and creating

\footnotetext{
* Corresponding author: ionela.rotaru@ulbsibiu.ro
} 
social change. [3] Connecting represents the major characteristics. Their unlimited connectivity to the digital technologies is underlined also by the fact that they are known also as "digital natives" [4]. That means not only unfettered electronic access to the information's, friends, instructors, classmates [3] through their own devices and social networks but also a current personal status highly influenced by this state of facts.

- Their experiences, perceptions, skills and needs are facts that must be taken in considerations long as all of these are reflecting in their expectations regards the educational process.

\section{Objective}

The major objective of this study is to model an algorithm that may be used in the practice classes of manufacturing technology. This objective must embody all the major needs presented above. It should be created a learning environment that enables learning by appealing to the specific characteristics of this generation. This are integrated into the teaching activity by the teaching methods used and it refers at issues like the ones presented below:

- collaborating, team working - the teacher role is to lad activities designed in order to facilitate the creation, structuring and retention of the required knowledge; the way to integrate it into the class activity is trough group discussions, Concept Map elaboration, results: this activity may eliminate the lack of attention, uses their natural abilities and in this way, engage the students in the proposed activities in and outside the classrooms;

- support active engagement in- and outside the class room - the teacher role is to prepare and sustain company visit with a specific topic, group discussions, design of concept maps; results: this activities helps the students to understand in profound the phenomena, eliminate the situations in which the participants doesn't know what should follow, has no questions, and the retained information is superficial.

\section{Methodology}

The paper presents a case study that started from the necessity of transforming aspects relating with: engaging of all students in the classroom, maintaining interest, a better understanding of issues and propose a combination of activities to ensure a better knowledge retention.

The participants were the students from the final year of Manufacturing Technology study program. Their profile is outlined in the following:

- age average: 22 years;

- female $19 \%$, male $81 \%$;

- foreign languages known: english $85,71 \%$, two foreign languages known 38,1\%, from wich 23,8\% english and german, 19\% english and french;

- $\quad$ activity on social networks: Facebook - 100\%, Instagram 28,9\%, WhatsApp 85,71\%, SnapChat 19\%;

- $\quad$ specific engineering software known: CATIA 85,71\%, Autocad 66,66\%, ProE 23,80\%;

- employed $61,90 \%$ from wich just one in a field other than engineering;

- $\quad$ hired by 10 months (the average);

- reasons behind the start of the activity: $54,4 \%$ experience, $33,33 \%$ experience and gain. 


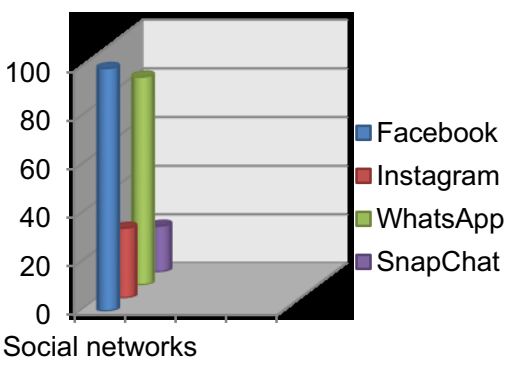

Social networks

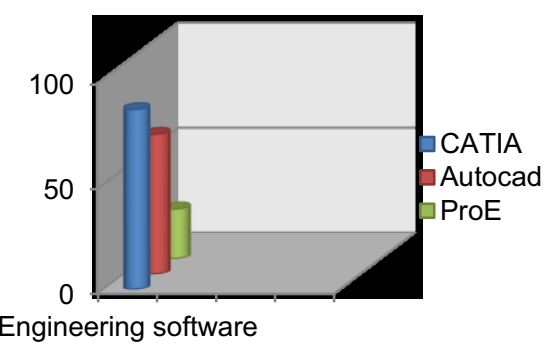

Fig. 1. Computer abilities: social and specific

All this underscores the unlimited access to information, the area of interest and the concerns that define them (closely related to digital technologies), the desire to learn and confirm the necessity to take into account this status that characterizes them.

In order to do this the first step consists in a systematic literature review on current teaching strategies, knowledge management and research concerning the profile of the present generation.

In the light of all these facts a solution is to treat the practical classes based on knowledge management principles. This means the transmission of knowledge in the most appropriate manner, taking into account the type of knowledge to be transmitted (charts, diagrams, tables, theorems, equation, videos, sketches, photos, effective machining - Figure 1) and capturing, structuring, presenting and storage the knowledge using Concept Maps. Their completion will do with a working visit designed so, that by cooperating of the teacher with the company representative the participants to be guided so that they can find, observe, understand and settle as many of the initial knowledge acquired over several practical classes. The first phase has already been checked over the years and the findings indicates its sustainability [6-7]. However the need for a qualitative improvement of the educational process led to the introduction of the second phase. Its stages consists of the steps presented below:

- preparing a file for each participant, the file contain a questionnaire and the technological process for the part to be followed along the process flow - an axe from a shock absorber - Figure 2;

- elaborating a questionnaire that highlights, grouped by series of questions, the knowledge gained over several practical classes - knowledge regarding the manufacturing process, component elements of a technological system, the structure of a technological process, the optimum sequence of operations, the specific technology for axes family. The questionnaire was distributed to the participants in the previous week of the visit and its role is to set a clear objective for the visit and to prepare the participants for it, allowing them to review the proposed subjects in order to identify the topics for wich them have questions. At the base of the questionnaire preparation there were the personal experience and reference works in the field, such as: Mechanical Engineering Design [8], Manufacturing Engineering and Technology [9], Standard Technologies [10], Workbook for Technology of Machine Tools [11], Manufacturing Technology [12], Engineering Design [13], Precision Machining Technology [14];

- at the beginning of the visit, the company representative highlight the functional role of the axe in the assembly shock absorber. In these way the necessity of each stage of the

- manufacturing process was underlined and the manufacturing process as a hole were better understood. Also, the hole technological flow was presented and explained from the warehouse of the semifinished part to the final product; 
- then followed the visit itself. At each workplace explanations have been given, the employers shared knowledge also, and the raised questions received answers;

- the final stage consists of discussion session in wich questionnaires have been brought and there were discussions sessions in order to evaluate the activity as completely as possible, there were bothe individual and group interviews.

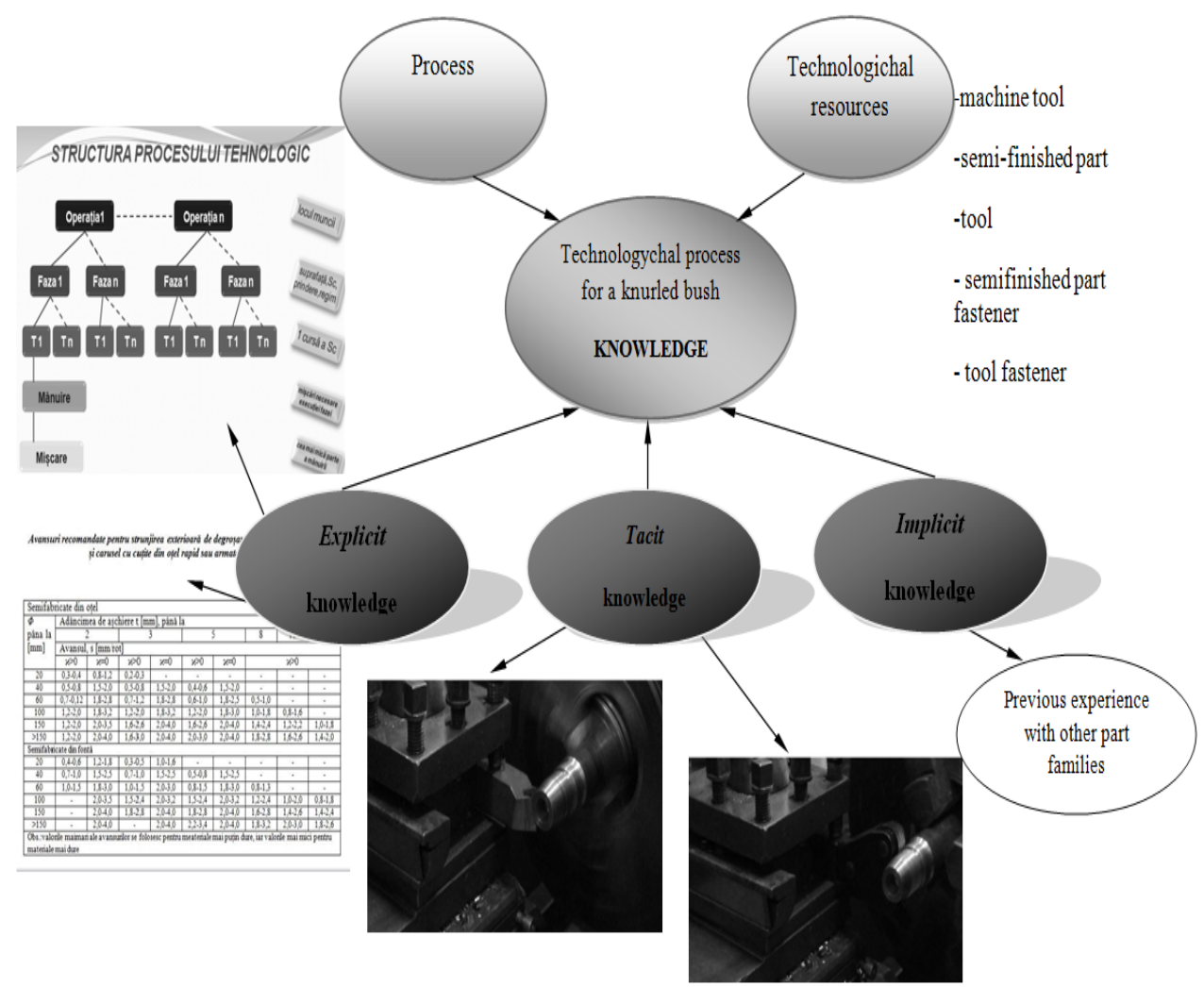

Fig. 2. Knowledge types and their transmission channels [6]

\section{Results and discussions}

In conclusion, it was proposed a learning improvement cycle wich brings together the practical and theoretical knowledge, the academical and companies environment and demands through sustainable principles dedicated to a group of people wich are characterized by the desire for active learning, connectivity, working in groups and, very important, with a major interest for knowledge acquisition when they understand their place in a current activity, when they see their finality. 


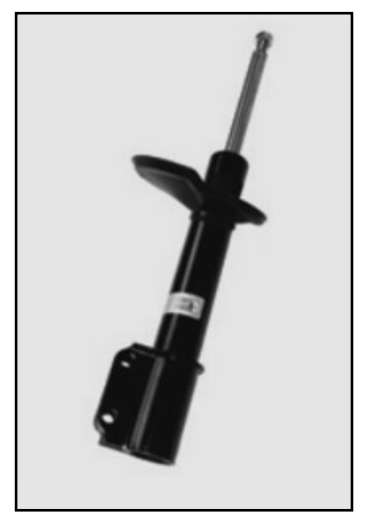

Fig. 3. Shock absorber http://www.thyssenkrupp-bilstein.de/en/produkte/2-rohr-daempfer.php

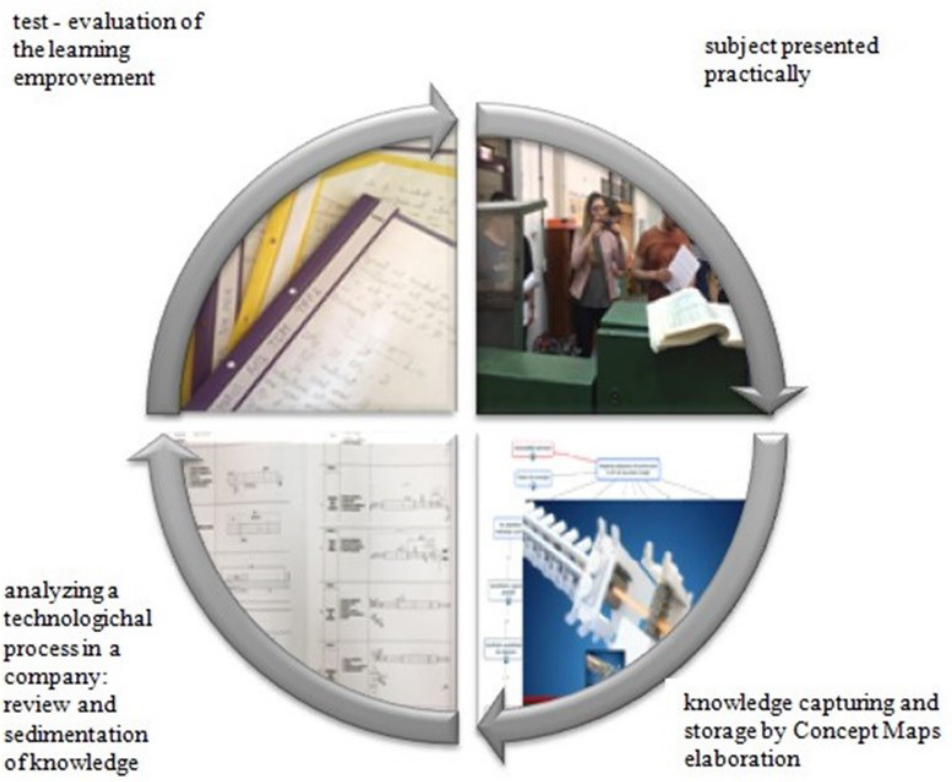

Fig. 4. Learning improvement cycle

The evaluation of the knowledge transfer was made by analyzing the questionnaires and by individual and group interviews. The questionnaires responses were scored on four points on Likert scale - 1 - insufficient, 2 - satisfactory, 3 - good and 4 very good. All the questions proposed in the questionnaire received responses. The quality of the responses is indicated by the test values $21,11 \%$ very good, $50,12 \%$ good, $19,16 \%$ satisfactory and $9,61 \%$ insufficient.

The questionnaire has a group of 32 questions grouped in six sections regarding: manufacturing process, component elements of a technological system, semifinished part, the structure of a technological process, the optimum sequence of operations, the specific technology for axes family.

At the first questions, regarding the part group/family from 36 forms only 2 was wrong.

From the group of question concerning the semifinised part everyones answers were good. Their responses to the 4 questions from the group (1. Which was the kind of the semifinished part elected? 2. Why. Justify the answer. 3 . Which was the first operation of the 
technological process? 4. Name another semifinished part for which the first operation would not be needed.).

The structure of the technological process had a group of 10 questions like: which is the first operation of the technical process? Which is the role of the first operation, which kind of operations (outside the machining operations) do we find? It would be a different process structure if we have just 8 parts to machine? Justify your answer. Each of them responded to the questions and even there were some wrong answers, it indicates a better understanding of the problem, the fact that the knowledge reached to them.

The student's perception was positive about the entire practice classes and regarding the visit, at the question "What do you liked concerning the visit?" they were having remarks as: "I find the visit interesting", "I like the idea and the initiative", "the fact that I saw the entire technological manufacturing process for the part", " the collaboration with the company representative and the professionalism with which the visit was treated". At the question "What didn't you like during the visit?" the responses was concerning the short time (two hours for a group), the number of participants from a group (around 12 participants), the fact that near the machines they could not hear the explanations very well.

In conclusion, active participation, the acquired knowledge, find their place and meaning in the complex mechanism of a producing company. The integration of knowledge in the reality indicates the finality of the hard work done and encourages the interest and sustained effort.

\section{References}

1. National Academy of Engineering, Adapting Engineering Education to the New Century, (Aviable at: http://c.ymcdn.com/sites/www.acectx.org/resource/resmgr/Learning_Center/ Educating_The_Engineer_of_20.pdf, 2005)

2. C. T., Kennedy, The Bridge, $\overline{\mathbf{3} 6}$ (2006)

3. T., Grover, C., Groscurth, Occasional Papers, Center for Research on Learning and Teaching, University of Michigan, 26 (2009)

4. M., Prensky, On the Horizon, 9 (5) (2001)

5. I. M. Rotaru, S. Borza, The 6th Balkan Region Conference on Engineering and Business Education \& The 5th International Conference on Engineering and Business Education \& The 4th International Conference on Innovation and Entrepreneurship, Sibiu, Romania, 1 (2011)

6. R. Budynas, K. Nisbett, Mechanichal engineering design, (Publisher McGraw-Hill Education, New-York, 2015)

7. S.Krar, A. Gill, P. Smid, Workbook for Technology of Machine Tools, (Publisher McGraw-Hill Education, New-York, 2011)

8. S. Kalpakian, S. Schmid, Manufacturing Engineering and Technology, (Publisher Prentice Hall, New-York, 2010)

9. D.M. Duse, O. Bologa, Tehnologii de prelucrare tipizate, (Publisher, Editura Universitatii Lucian Blaga din Sibiu, Sibiu, 1995)

10. P. N. Rao, Manufacturing Technology, (Publisher McGraw-Hill Education,India, 2013)

11. G. E. Dieter, L.C. Schmidt, Engineering Design, (Publisher McGraw-Hill Education, New-York, 2009) 